Revista de

Contabilidade e

Organizações

www.rco.usp.br
DOI: http://dx.doi.org/10.11606/issn.1982-6486.rco.2019.144322
Journal of

Accounting and

Organizations

www.rco.usp.br

\title{
Valores culturais e estilos de aprendizagem dos operadores da contabilidade do setor público brasileiro frente ao processo de adoção das normas internacionais
}

Cultural values and learning styles of Brazilian public sector accounting operators in the process of adopting international standards

Antonio Firmino da Silva Neto ${ }^{\mathrm{a}}$; José Dionísio Gomes da Silva ${ }^{\mathrm{b}}$

${ }^{a}$ Universidade Federal de Campina Grande

${ }^{b}$ Universidade Federal do Rio Grande do Norte

Palavras-chave

Adoção das IPSAS.

Dimensões culturais.

Estilos de aprendizagem.

Operadores da contabilidade.

Comunidade epistêmica.

Keywords

Adoption of IPSAS.

Cultural dimensions.

Learning styles.

Accounting operators.

Epistemic community.
Informações do Artigo

Recebido: 14 de março de 2018

Aceito: 24 de abril de 2019

Publicado: 06 de maio de 2019

\section{Resumo}

O objetivo deste estudo é analisar os valores culturais e estilos de aprendizagem dos operadores da contabilidade, que formam a comunidade epistêmica da adoção das IPSAS no Brasil. Utilizou-se a teoria dos valores culturais de Hofstede (1980) e a aprendizagem experiencial de Kolb (1984) na formatação do questionário. Obtevese uma amostra de 426 respondentes de todos os estados brasileiros. A comunidade epistêmica envolvida no desenho ou ensino das normas (normatizadores) e na operação e adoção (executores federal, estadual e municipal) apresentam valores culturais de distância hierárquica equilibrada, coletivismo, feminilidade, baixa aversão à incerteza e alta orientação de longo prazo. O estilo de aprendizagem é diferente entre executores contábeis nos níveis federal e estadual, quando comparados com o nível municipal. Enquanto no primeiro grupo (federal e estadual) os executores utilizam reflexões abstratas, os executores do segundo grupo (municipal) são propensos a ter um aprendizado baseado em experiências concretas e casos práticos. Na prática das organizações públicas devem ser realizados treinamentos com diferentes concepções de aprendizagem, incluindo as iniciativas de disseminação das IPSAS.

\begin{abstract}
We analyze the cultural values and learning styles of accounting professionals from the epistemic community working on the IPSAS adoption in Brazil. We used the theory of cultural values of Hofstede (1980) and the experiential learning of Kolb (1984) to formulate the questionnaire. We collected responses from 426 respondents from all Brazilian states. The epistemic community involved in the design or teaching of norms (regulators) and in the operation and adoption (federal, state and municipal executors) present cultural values of Hierarchical Balanced Distance, Collectivism, Femininity, Low Aversion to Uncertainty and high Long-Term Orientation. The learning style is different among federal and state accounting executors, compared to municipal one. For the first group (feral and state) the executors operate based on abstract reflections, and for the second group (municipal) the executors has a learning style based on concrete experiences and practical cases. In practice, the public organizations must provide trainings programs based on distinct learning conceptions, including those applied on IPSAS training initiatives.
\end{abstract}

\section{Implicações práticas}

As entidades governamentais - normatizadoras e executoras - ao desenhar treinamentos para disseminação das IPSAS podem considerar os diferentes estilos de aprendizagem predominantes. Nos níveis estadual e federal, executores de contabilidade atuam como "assimiladores", mas no nível municipal, o estilo é o "divergente", indicando que os treinamentos adequados são distintos para os dois grupos.

Copyright $(92019$ FEA-RP/USP. Todos os direitos reservados 


\section{INTRODUÇÃO}

A adoção das International Public Sector Accounting Standards - IPSAS tem sido fenômeno estudado mundialmente, e a implementação das normas não tem sido livre de dificuldades e de críticas. A adoção das IPSAS vem da convicção de que tais normas melhoram a comparabilidade das informações financeiras e facilitam a consolidação das demonstrações contábeis (Christiaens et al., 2015), "além de promover uma maior accountability governamental, melhorar a gestão, a disciplina financeira e a harmonização internacional das exigências de informação" (IFAC, 1996, p. 2).

A adoção das IPSAS no Brasil se intensificou em 2008, com a publicação, pelo Ministério da Fazenda, da Portaria $\mathrm{n}^{\circ} 184$, impulsionando o processo de convergência das práticas contábeis vigentes no setor público brasileiro. Contudo, o processo brasileiro vem enfrentando desafios e já foi prorrogado por diversas ocasiões. Entre os motivos para essa demora estão: (a) dificuldade na capacitação dos profissionais e na aceitação do regime de competência; (b) adaptação à nova fase da contabilidade, com a criação de novos instrumentos de informação e controle do sistema público; e (c) diferenças culturais que desempenha um papel importante no processo de adoção das IPSAS e das reformas do setor público (Diniz et al., 2015).

As diferenças culturais, o contexto histórico ou os elementos estruturais de cada país são apontados como fatores que afetam as reformas e os sistemas de contabilidade (Benito, Brusca \& Montesinos, 2007; Pina, Torres \& Yetano, 2009). Para Brusca e Condor (2002) e Pina e Torres (2003), os sistemas de contabilidade de cada país tendem a ser desenvolvidos em função de diferentes atributos culturais. Tais diferenças culturais podem impactar o processo de adoção das IPSAS (Brusca \& Condor, 2002; Weffort, 2005; Diniz et al., 2015). A cultura então é vista como uma das causas prováveis para as diferenças contábeis em nível internacional (Weffort, 2005), sendo capaz de exercer influência nas normas e práticas contábeis, tanto diretamente, afetando o comportamento do contador e dos usuários das demonstrações contábeis, como indiretamente, por intermédio das principais instituições do país.

As mudanças exigem uma nova cultura, por parte dos contadores, que não se altera facilmente, na aceitação dos novos procedimentos, em busca de uma contabilidade patrimonial, ao invés de uma contabilidade orçamentária (Jorge, 2003).Ainda, para disseminação de tais práticas, o processo de aprendizagem organizacional seria determinante para assimilação de novas ideias. Tal aprendizagem viria da experiência direta e, também, da ativa intervenção dos facilitadores e dos consultores, para incrementar as práticas dos indivíduos e das organizações (Antonello \& Godoy, 2010).

Dado que a cultura e aprendizagem afetariam o processo, o presente artigo pretende identificar quais os principais traços culturais dos atores envolvidos no processo de reforma e como esses se relacionam com o estilo de aprendizado utilizado por eles. Tais atores são aqui denominados de "comunidade epistêmica" (Antipova \& Bourmistrov, 2013, p. 447). Esses atores são responsáveis tanto pelo desenho da norma quanto pela sua implantação nas organizações, e teriam a capacidade de promover a aprendizagem organizacional (Diniz et al., 2015). Assim, seria desejável e necessária a discussão entre tais atores para uma mudança mais efetiva das práticas contábeis nas organizações (Diniz et al., 2015).

Adotamos instrumentos de pesquisa elaborados com base nos valores culturais de Hofstede (1980) e na teoria da aprendizagem experiencial de Kolb (1984), e aplicamos o questionário a 426 profissionais considerados a "comunidade epistêmica" da adoção das IPSAS no Brasil.

\section{VALORES CULTURAIS E ESTILOS DE APRENDIZAGEM}

A cultura e a aprendizagem são componentes que as pessoas carregam e que podem ser levados em consideração pelas organizações. A cultura pode ser compreendida como "a programação coletiva da mente que distingue os membros de um grupo humano de outro" (Hofstede, 1980, p. 25). A cultura pode ser revelada a partir de valores, por meio de programas mentais que surgem no espaço familiar, mas que podem ser alterados ou reforçados nas instituições, escolas e organizações (Hofstede, 2001). Assim, é necessário que as entidades entendam os diferentes valores culturais que predominam entre pessoas e que podem impactar a adoção de novas rotinas e mudanças que estão ocorrendo.

A cultura influencia o comportamento individual e coletivo. Os modelos culturais se baseiam em sistemas de valores, que apesar de serem um dos níveis de manifestação da cultura observáveis, são mais difíceis de serem alterados (Hofstede, 1980). 
A pesquisa de Hofstede buscou detectar os elementos estruturais da cultura e, particularmente, aqueles que eram mais influentes no comportamento em situações de trabalho nas organizações e nas instituições (Radebaugh, 2002). Com isso identificou os padrões culturais e suas diferenças transnacionais, baseados nas diferentes formas de aprender problemas semelhantes. Além de Hofstede (1980), Gray (1988) é uma das referências para identificar os valores culturais predominantes numa sociedade.

A cultura pode ser considerada o reflexo de padrões de comportamento transmitido socialmente e obtido por meio da aprendizagem. Por isso sugere-se que as pesquisas interculturais levem em consideração a cultura nacional no que tange à homogeneidade e heterogeneidade dos valores cultuais (Tung, 2008). Os valores culturais apresentados pela teoria de Hofstede (1980, 2001) são: (a) distância hierárquica - grande ou pequena; (b) individualismo, ou seja, o comportamento contrário ao coletivismo; (c) masculinidade, neste caso o comportamento oposto é a feminilidade; (d) aversão à incerteza - elevada ou baixa; e (e) orientação de longo prazo - alta ou baixa. O Brasil foi incluído na amostra do estudo de Hofstede (1980), e a sociedade brasileira apresentou como comportamento típico, os traços de: aceitar grande distância hierárquica, coletivismo, masculinidade, elevada aversão à incerteza e alta orientação de longo prazo.

Se a cultura é reforçada no ambiente de trabalho, a aprendizagem também pode se dar no ambiente de trabalho, ou nas relações profissionais associadas a tal ambiente. A aprendizagem pode ser uma forma de transmitir a cultura, e a cultura pode ser um contexto relevante para forma como os processos de aprendizagem ocorrem. A aprendizagem aqui é vista como um processo adaptativo holístico, em quatro dimensões inter-relacionadas: estrutura afetiva, estrutura perceptual, estrutura simbólica e estrutura comportamental (Kolb, 1984). O processo de aprendizagem nas organizações é impactado pela aprendizagem individual (Kolb, 1971), pois cada indivíduo pode ter um estilo de aprendizagem predominante. Os estilos de aprendizagem de uma pessoa seriam um "estado duradouro e estável que deriva de configurações consistentes das transações entre o indivíduo e o meio no qual ele está inserido" Kolb (1984, p. 24).

A teoria da aprendizagem experiencial de Kolb (1984) vê a aprendizagem como um processo reflexivo que envolve duas dimensões - perceber e processar. A dimensão “perceber" é constituída pelos aspectos concreto e abstrato, e a "processar" é composta pelos aspectos ativo e reflexivo. Assim, os indivíduos podem aprender pela presença predominante de um dos quatro estilos de aprendizagem: (a) acomodador; (b) divergente; (c) assimilador; e (d) convergente.

A cultura e a aprendizagem estariam associados ao comportamento dos profissionais 'operadores da contabilidade', sobretudo em relação ao processo de adoção das IPSAS.

\section{METODOLOGIA}

A pesquisa é baseada na coleta de percepção e comportamento de respondentes do que chamamos aqui de “comunidade epistêmica" (Antipova \& Bourmistrov, 2013, p. 447), a qual atua no processo de adoção das IPSAS no Brasil. Essa comunidade seria formada pelo conjunto de 'operadores da contabilidade' que identificamos estarem 'envolvidos no desenho ou ensino das normas' (normatizadores) e aqueles 'envolvidos na operação e adoção’ (executores) das IPSAS no Brasil.

Consideramos a população de normatizadores, ou seja, aqueles que estão envolvidos com o desenho das IPSAS no nível federal, estadual e capitais dos estados, totalizando 4.775 operadores (Brasil, 2016). Os normatizadores são membros dos grupos: a) Técnico de Padronização de Procedimento Contábeis, atual Câmara Técnica de Normas Contábeis e de Demonstrativos Fiscais da Federação da Secretaria do Tesouro Nacional, composta por 31 membros efetivos $^{1}$ e 120 convidados; b) Gestores das Finanças Estaduais (27 contadores gerais); e c) Gestores Financeiros das Capitais (27 contadores gerais). Já os executores, num total de 4.570 profissionais em toda federação, são contadores e técnicos em contabilidade federais, estaduais e das capitais que executam as rotinas contábeis.

\footnotetext{
${ }^{1}$ Os membros efetivos são: Subsecretario de Contabilidade Pública do Tesouro Nacional, Coordenador-Geral de Normas de Contabilidade Aplicadas à Federação, cinco representantes do Poder Executivo Federal, seis representantes dos estados e do Distrito Federal, quatro representantes dos municípios, além de representantes do Ministério Público, Câmara dos Deputados, Senado e Tribunais de Contas. Os dois primeiros também são membros do Grupo Assessor do Conselho Federal de Contabilidade que elaboram as Normas Brasileiras de Contabilidade Aplicadas ao Setor Público
} 
O questionário foi dividido em duas partes, e pode ser consultado no Apêndice A. Na primeira parte, o respondente indica, em 20 questões com escala likert, seus valores culturais, a partir da adaptação do Value Survey Module 1994 desenvolvido por Hofstede (1980). Na segunda parte, procura-se captar o estilo de aprendizagem de forma contextualizada na adoção de normas contábeis. É proposto ao respondente uma mini vinheta: "imagine que você desenvolve suas atividades profissionais de contabilidade para uma (ou em uma) entidade do setor público. A contabilidade do setor público está passando por mudanças de normatização. Será necessária a adoção de normas internacionais (IPSAS). Portanto, será necessário aprender.

Para os 12 itens da escala de Kolb (1999), traduzida por Cerqueira (2000), o respondente ordena de 1 (menos provável) a 4 (mais provável) o estilo que ele(a) adotaria, por exemplo, ao aprender a lidar com sentimentos, ao pensar sobre ideias, ao fazer coisas, ou ao observar, ver e escutar.

O contexto colocado seria o de aprendizado de normas contábeis. Apesar de nem todos os respondentes trabalharem efetivamente com as normas contábeis ou com sua implementação, a proposta de sugerir uma situação hipotética tem objetivo de conectá-los mais próximo possível do contexto da adoção das normas. O fato de não ser perguntado ao respondente qual sua real ocupação é uma estratégia para evitar a diferenciação de que alguns podem viver tal realidade no seu dia a dia, e outros não. Os que vivem tal realidade no dia a dia, terão certo distanciamento, dada forma que foi feita a questão, os que não vivem terão certa aproximação. Os autores reconhecem que existem limitações no método, não se trata de um experimento, apenas do uso de uma mini vinheta para suscitar um contexto similar a todos os respondentes.

A coleta dos dados foi de junho de 2016 a fevereiro de 2017. Primeiro, aplicamos o questionário pessoalmente em eventos nacionais e regionais em cinco diferentes estados. Nestes eventos, os 'operadores da contabilidade' eram o público-alvo. Antes de começar a aplicação, informou-se aos respondentes o objetivo da pesquisa e como deveria ser o preenchimento. A aplicação in loco se deu nos seguintes eventos, que juntos totalizaram 511 participantes:

- Fórum de Controle Externo, promovido pelo Tribunal de Contas do Estado do Paraná, em Curitiba (evento de abrangência regional realizado nos dias 01 e 02 de junho de 2016);

- Fórum do grupo Notícias Contábeis do Setor Público, em João Pessoa - PB (evento de abrangência regional realizado no dias 18 de agosto de 2016);

- Pós-graduação lato sensu em Finanças Públicas e Administração Orçamentária, promovido pela Escola de Governo Henrique Santillo, em Goiânia - GO (evento de abrangência regional realizado nos dias 26 e 27 de agosto de 2016);

- Treinamento para contadores promovido pela Escola de Administração e Treinamento, em Vitória - ES (evento de abrangência regional realizado nos dias 19 e 20 de agosto de 2016);

- Encontro do Grupo Técnico de Padronização de Procedimento Contábeis, em Brasília - DF (evento de abrangência nacional realizado de 09 a 11 de novembro de 2016);

- Semana de Administração Orçamentária, Financeira e de Contratações Públicas, promovida pela Escola de Administração Fazendária, em Brasília - DF (evento de abrangência nacional realizado de 28 de novembro a 02 de dezembro de 2016).

Posteriormente, enviamos o questionário por meio de correio eletrônico (e-mail) para a lista de contatos dos contabilistas que atuam no setor público. Buscou-se, em órgãos oficiais (Conselho Federal de Contabilidade, Secretaria do Tesouro Nacional e Associação Nacional dos Contabilistas do Poder Executivo Federal), um banco de dados que englobasse todos os contabilistas federais, estaduais e municipais. A lista de e-mails mais completa foi cedida pela Associação Nacional dos Contabilistas do Poder Executivo Federal, contudo nela só constavam contabilistas federais ( 688 contadores e 887 técnicos em contabilidade).

A taxa de retorno dos 1.575 questionários enviados foi de aproximadamente $9,21 \%$, dos quais $95,2 \%$ foi de contadores e $4,8 \%$ de técnicos. Na tentativa de aumentar a taxa de retorno, reenviamos os e-mails duas vezes por semana, geralmente nas terças e quintas-feiras, expurgando do reenvio aqueles respondentes que já haviam dado um feedback. Optou-se por não utilizar qualquer tipo de plataforma para o questionário, pois se buscou agradecer a cada e-mail respondido no intuito de demonstrar a importância da participação de cada um dos respondentes na conclusão desta pesquisa.

Obtivemos 426 respostas (acima das 356 respostas para um grau de confiança de 95\%), sendo 281 coletadas pessoalmente, e 145 coletadas via e-mails. Dos respondentes, $98 \%$ têm no mínimo curso superior, e $84 \%$ são contadores de formação (descrição da amostra detalhada no Apêndice B). 
Na análise, comparamos os dois grupos mencionados da comunidade epistêmica, e observamos como varia os valores culturais e o estilo de aprendizagem. Na análise da aprendizagem, chegamos ao estilo de aprendizagem predominante de uma pessoa combinando as dimensões perceber e processar, utilizando os conceitos do ciclo de aprendizagem de Kolb (1984).

O ciclo de aprendizagem em Kolb (1984) é formado por aspectos estruturais (conceituação abstrata, experiência concreta, experiência ativa e observação reflexiva), dimensões (perceber e processar) e estilos de aprendizagem (divergente, assimilador, convergente e acomodador). Os aspectos estruturais, conceituação abstrata e experiência concreta, formam a dimensão 'perceber', e experiência ativa e observação reflexiva a dimensão 'processar'. Quando os pontos das dimensões perceber e processar são interligados no plano cartesiano encontrase o estilo de aprendizagem predominante de uma pessoa.

\section{VALORES CULTURAIS DOS 'OPERADORES DA CONTABILIDADE' DO SETOR PÚBLICO BRASILEIRO}

A análise foi realizada, inicialmente, levando em consideração dois grupos: a) envolvidos no desenho ou ensino das normas, os quais caracterizamos como normatizadores e; b) envolvidos na operação e adoção, neste caso os executores federal, estadual e municipal. Em seguida, a análise foi realizada sem dividir os executores em federal, estadual e municipal.

Esta seção apresenta a análise dos valores culturais: distância hierárquica (grande/pequena), aversão à incerteza (elevada/baixa), individualismo/coletivismo, masculinidade/feminilidade e orientação de longo prazo (alta/baixa), que estão relacionados ao comportamento dos 'operadores da contabilidade' do setor público brasileiro. A Tabela 1 expressa os resultados do teste Kruskal-Wallis da relação entre valores culturais e dos grupos normatizador e executor.

Tabela 1. Comparação dos valores culturais por grupo normatizador versus executor federal, estadual e municipal

\begin{tabular}{|c|c|c|c|c|c|}
\hline \multirow{4}{*}{ Valores culturais } & \multicolumn{4}{|c|}{ Grupo } & \multirow{4}{*}{$\begin{array}{c}\text { Kruskal- } \\
\text { Wallis }\end{array}$} \\
\hline & \multirow{2}{*}{ Normatizador } & \multicolumn{3}{|c|}{ Executor } & \\
\hline & & Federal & Estadual & Municipal & \\
\hline & Média & Média & Média & Média & \\
\hline Distância Hierárquica & 51,17 & 50,98 & 48,88 & 53,11 & 0,627 \\
\hline Aversão à incerteza & 42,52 & 36,30 & 39,20 & 37,99 & 0,011 \\
\hline Individualismo & 39,01 & 40,26 & 42,26 & 40,59 & 0,578 \\
\hline Masculinidade & 46,38 & 48,68 & 41,96 & 44,10 & 0,167 \\
\hline Orientação de longo prazo & 60,44 & 56,57 & 64,24 & 58,79 & 0,067 \\
\hline
\end{tabular}

Fonte: Dados da pesquisa.

Nota: Os índices dos valores culturais podem variar numa escala de 0 a 100.

Observa-se que há diferença significativa entre os grupos apenas no valor cultural "aversão à incerteza", sendo esta a única característica cultural que diferencia aqueles que estão envolvidos no desenho ou ensino das normas daqueles envolvidos na operação e adoção. Portanto, o grupo ao qual é classificado o operador da contabilidade influencia nessa dimensão da cultura. Por outro lado, não existem diferenças nos valores culturais entre os que normatizam e os que executam, no que tange a distância hierárquica, individualismo, masculinidade e orientação de longo prazo.

Realizaram-se testes multivariados da MANOVA (Tabela 2) para avaliar as diferenças significativas nos valores culturais e estilos de aprendizagem com o objetivo de ratificar o teste de variância univariada KruskalWallis.

Tabela 2. Testes multivariados da MANOVA para avaliar diferenças significativas no aspecto cultura por grupo

\begin{tabular}{llcc}
\hline \multicolumn{1}{c}{ Teste multivariado } & Valor & F & Valor-p \\
\hline Traço de Pillai & 0,061 & 1,753 & 0,036 \\
Lambda $(\lambda)$ de Wilks & 0,940 & 1,756 & 0,036 \\
Traço de Hotelling & 0,063 & 1,756 & 0,036 \\
Maior autovalor de Roy & 0,040 & 3,401 & 0,005 \\
\hline
\end{tabular}

Fonte: Dados da pesquisa. 
A Tabela 2 mostra que todos os testes multivariados da MANOVA com variável dependente as dimensões da cultura e variável independente (fator) grupo, apresentam resultado significativo, demonstrando que as médias das dimensões da cultura variam significativamente por grupo. A análise de variância univariada mostra que essa diferença é causada pela componente aversão à incerteza. Além dessa análise, que dividiu os executores em federal, estadual e municipal, foi realizada o agrupamento desses três em uma única variável para verificar se haveria alteração nos resultados.

Tabela 3. Comparação dos valores culturais por grupo normatizador versus executor

\begin{tabular}{lccc}
\hline \multicolumn{1}{c}{ Valores culturais } & Mann-Whitney U & Wilcoxon $\mathbf{W}$ & Mann-Whitney \\
\hline Distância Hierárquica & 19256,50 & 28709,50 & 0,649 \\
Aversão à incerteza & $\mathbf{1 6 2 2 8 , 0 0}$ & $\mathbf{5 8 1 3 3 , 0 0}$ & $\mathbf{0 , 0 0 3}$ \\
Individualismo & 18561,50 & 28014,50 & 0,297 \\
Masculinidade & 19373,00 & 61278,00 & 0,721 \\
Orientação de longo prazo & 18412,50 & 60317,50 & 0,199 \\
\hline
\end{tabular}

Fonte: Dados da pesquisa.

O teste de Mann-Whitney é realizado para dois grupos independentes e apresenta o mesmo resultado encontrado pela estatística de Kruskal-Wallis. Logo, rejeita-se que a distribuição de aversão à incerteza é a mesma entre as categorias de grupo. Conforme a Tabela 1, os executores federal e municipal têm o menor índice de aversão à incerteza. De acordo Hofstede (1991), indivíduos com baixa aversão à incerteza são menos influenciados pela pressão social e assumem mais riscos na adoção de algo novo. Nesta pesquisa, "algo novo" seria as IPSAS, conforme é apresentado na vinheta do instrumento (Apêndice A). Por outro lado, não existem diferenças nos demais valores culturais daqueles que atuam no desenho e ensino das normas e os que atuam na operacionalização.

Ademais, efetuados os cálculos dos índices dos valores culturais conforme fórmulas desenvolvidas por Hofstede (1980, 2001), e determinada a média (ver Tabela 1) das afirmativas do instrumento (Apêndice A), é possível afirmar que tanto normatizadores como executores (federal, estadual e municipal) têm características de valores culturais de coletivismo, feminilidade, distância hierárquica equilibrada, baixa aversão à incerteza e alta orientação de longo prazo. Os resultados são semelhantes aos de Rodrigues (2010) e Hamann (2011).

Hofstede $(1980,2001)$ explica de forma sucinta cada um desses valores, os quais servem de parâmetros para caracterizar a cultura dos operadores. Assim, pode-se afirmar com base nos resultados encontrados, e fundamentado na teoria dos valores culturais de Hofstede (1980, 2001), que os 'operadores da contabilidade' do setor público preferem ambiente de trabalho coletivista; chefes (gestores, gerentes, administradores dentre outros) menos autoritários e que dialogam com seus subordinados; priorizam oportunidades de treinamento para melhorar as habilidades e esperam poder usá-las no ambiente de trabalho; acentua-se a igualdade, a solidariedade e a qualidade de vida no trabalho; entendem que os conflitos devem ser resolvidos por meio da negociação e do compromisso; preservam o comprometimento ético, altos valores para educação e respeito pela tradição, perseverança e lealdade. Conhecer essas características culturais possibilita, por exemplo, as entidades traçarem estratégias para uma aprendizagem das normas; entender que chefes autoritários vão ter mais dificuldades do que os gerentes que dialogam com seus subordinados.

Os resultados da pesquisa também permitem demonstrar que os valores culturais distância hierárquica (equilibrada) e aversão à incerteza (baixa) dos 'operadores da contabilidade' do setor público brasileiro são diferentes de Hofstede (2001). A cultura de uma sociedade pode ser o reflexo de um grupo de profissionais que tenha presença em todas as regiões do país Hofstede (2001). Ressalta-se que a amostra desta pesquisa tem representantes de todos os estados do Brasil e contempla as cinco regiões (Norte, Nordeste, Sul, Sudeste e Centro-Oeste). Assim, o resultado pode ser utilizado para indicar que a cultura da sociedade brasileira, representada pelos 'operadores da contabilidade', está em processo de mudança.

Portanto, conhecer os valores culturais dos 'operadores da contabilidade' do setor público brasileiro possibilita que as entidades do setor público orientem suas políticas de capacitação, treinamento e disseminação das IPSAS observando comportamentos culturais desses agentes, para que uma efetiva adoção das normas ocorra. 


\section{ESTILOS DE APRENDIZAGEM DOS 'OPERADORES DA CONTABILIDADE' DO SETOR PÚBLICO BRASILEIRO}

Esta seção apresenta os estilos de aprendizagem dos 'operadores da contabilidade' do setor público brasileiro. A Tabela 4 evidencia os resultados do teste qui-quadrado da relação entre estilos de aprendizagem e grupo normatizador e executor federal, estadual e municipal.

Tabela 4. Comparação dos estilos de aprendizagem por grupo normatizador versus executor federal, estadual e municipal

\begin{tabular}{|c|c|c|c|c|c|c|c|c|c|}
\hline \multirow{4}{*}{$\begin{array}{c}\text { Estilo de } \\
\text { aprendizagem }\end{array}$} & \multicolumn{8}{|c|}{ Grupo } & \multirow{4}{*}{$\begin{array}{c}\text { Qui- } \\
\text { quadrado } \\
\text { (valor-p) }\end{array}$} \\
\hline & \multicolumn{2}{|c|}{ Normatizador } & \multicolumn{6}{|c|}{ Executor } & \\
\hline & & & \multicolumn{2}{|c|}{ Federal } & \multicolumn{2}{|c|}{ Estadual } & \multicolumn{2}{|c|}{ Municipal } & \\
\hline & $\mathrm{N}$ & $\%$ & $\mathrm{~N}$ & $\%$ & $\mathrm{~N}$ & $\%$ & $\mathrm{~N}$ & $\%$ & \\
\hline Divergente & 19 & 4,5 & 20 & 4,7 & 5 & 1,2 & 20 & 4,7 & \\
\hline Assimilador & 64 & 15,0 & 60 & 14,1 & 16 & 3,8 & 40 & 9,4 & \\
\hline Convergente & 41 & 9,6 & 37 & 8,7 & 9 & 2,1 & 34 & 8,0 & 0,478 \\
\hline Acomodador & 13 & 3,1 & 23 & 5,4 & 3 & 0,7 & 22 & 5,2 & \\
\hline Total & 137 & 32,2 & 140 & 32,9 & 33 & 7,7 & 116 & 27,2 & \\
\hline
\end{tabular}

Fonte: Dados da pesquisa.

O teste qui-quadrado da Tabela 5 foi realizado sem dividir o grupo dos executores em federal, estadual e municipal. Dessa forma, o teste considerou dois grupos normatizador e executor.

Tabela 5. Comparação dos estilos de aprendizagem por grupo normatizador versus executor

\begin{tabular}{lccc}
\hline & Valor & df & Sig. Assint. (2 lados) \\
\hline Qui-quadrado de Pearson & $4,586 \mathrm{a}$ & 3 & 0,205 \\
Razão de verossimilhança & 4,823 & 3 & 0,185 \\
Casos Válidos & 426 & & \\
\hline
\end{tabular}

Fonte: Dados da pesquisa.

A análise dos testes qui-quadrado, que verifica de forma individualizada as variáveis estilos de aprendizagem, demonstra que nenhum dos estilos da aprendizagem explica de forma significativa a diferença por grupo, seja na Tabela 4 seja na Tabela 5. Assim, não se verifica influência do grupo sobre o estilo de aprendizagem (valor-p $>0,05)$.

Por outro lado, ao realizar o teste qui-quadrado sem distinguir os operadores em normatizadores e executores, encontra-se diferença estatística no estilo de aprendizagem (valor-p $<0,001$ ). Observa-se na Tabela 6 que o estilo de aprendizagem predominante é o assimilador (42,3\%).

Tabela 6. Teste qui-quadrado de Pearson para análise dos estilos de aprendizagem dos operadores da contabilidade do setor público brasileiro

\begin{tabular}{lccc}
\hline Estilos de aprendizagem & N & $\mathbf{\%}$ & Valor-p* $^{*}$ \\
\hline Divergente & 64 & 15,0 & \\
Assimilador & 180 & 42,3 & $<0,001$ \\
Convergente & 121 & 28,4 & \\
Acomodador & 61 & 14,3 & \\
Total & 426 & 100,0 & \\
\hline
\end{tabular}

Fonte: Dados da pesquisa.

Nota: *Teste qui-quadrado.

Para melhor entendimento das associações entre as categorias, aplicou-se a estatística de análise de correspondência, que pode ser observada na Tabela 7, levando em consideração o grupo executor dividido em normatizador, executor federal, estadual e municipal. 
Tabela 7. Análise de correspondência aplicada ao cruzamento estilos de aprendizagem por grupo normatizador versus executor federal, estadual e municipal

\begin{tabular}{cccccc}
\hline Eixos ou dimensões & Valor singular & Inércia & Qui-quadrado & Valor-p & \% inércia \\
\hline 1 & 0,134 & 0,018 & & & 89,6 \\
2 & 0,043 & 0,002 & & 9,2 \\
3 & 0,015 & 0,000 & 8,570 & 0,478 & 1,2 \\
Total & & $\mathbf{0 , 0 2 0}$ & & & $\mathbf{1 0 0 , 0}$ \\
\hline
\end{tabular}

Fonte: Dados da pesquisa.

A Tabela 7 apresenta uma solução da aplicação da análise de correspondência com número de dimensões igual a $3(=\min \{4-1,4-1\}=3)$, em que a terceira dimensão explica apenas $1,2 \%$ da inércia (variação) total, sendo, portanto preferível a solução com duas dimensões, em que o eixo 1 apresenta $89,6 \%$ da inércia total e o eixo 2 possui $9,2 \%$.

Por meio da normalização simétrica da análise de correspondência da Figura 1, observa-se que os normatizadores e executores federais e estaduais formam um cluster com predominância do estilo de aprendizagem assimilador. Com base na teoria da aprendizagem experiencial de Kolb (1984), pessoas com estilo assimilador utilizam raciocínio indutivo, preferem pensar, refletir e planejar; fundamentam seu aprendizado nos modelos teóricos e dificilmente deixam-se guiar por seus sentidos; são hábeis para criar modelos abstratos e teóricos, mas há pouca preocupação com o uso prático dessas teorias. Já os executores municipais apresentam estilo de aprendizagem divergente. Os divergentes conseguem relacionar o conteúdo que estão aprendendo com suas experiências, são habilidosos em situações que demandam ideias novas (brainstorming) e criativas e que exigem capacidade de compreensão das pessoas. Aprendem pela experiência concreta e observação reflexiva. A didática de ensino mais efetiva para esse tipo de aprendiz é aquela que envolve casos e experiência práticos.

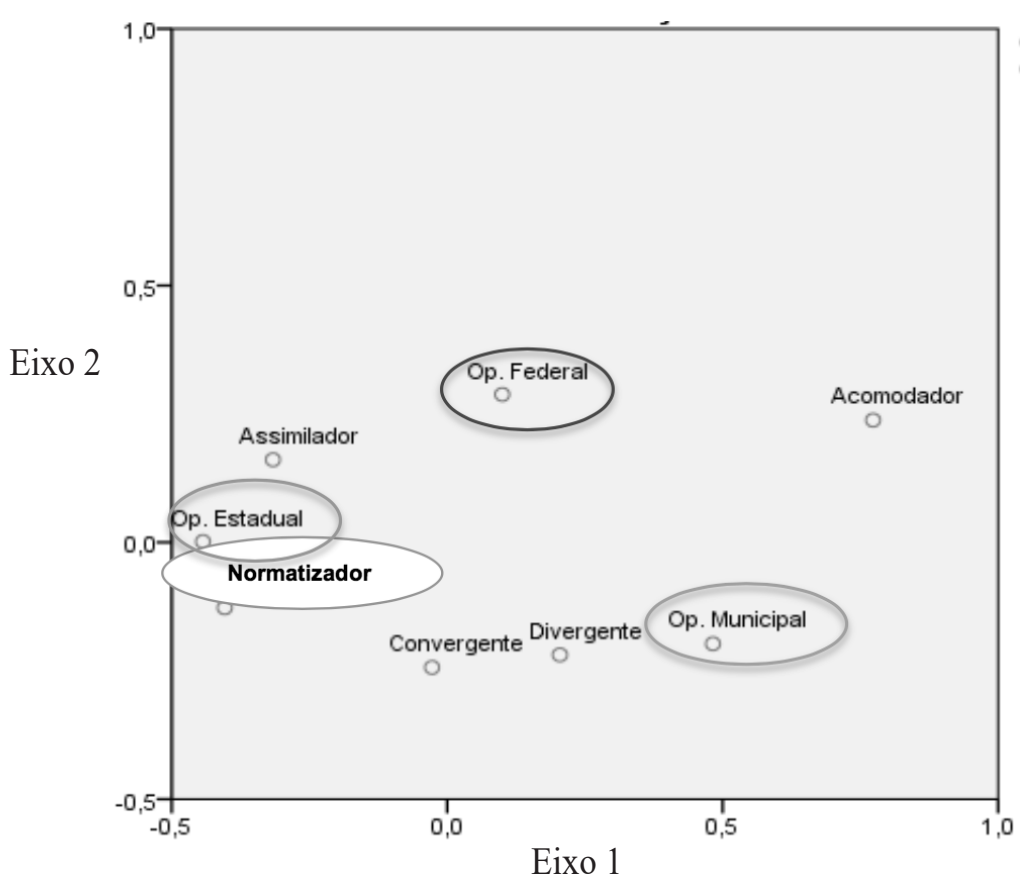

Figura 1. Mapa de associação da análise de correspondência para o cruzamento das variáveis estilos de aprendizagem e grupo

Fonte: Dados da pesquisa. 
Portanto, com base no estilo de aprendizagem predominante entre os 'operadores da contabilidade', as entidades governamentais podem direcionar suas estratégias de treinamentos focadas numa estrutura de ensino que atenda às características de aprendizagem assimiladora para uma efetiva adoção. Identificar como os operadores aprendem facilita o processo de adoção das IPSAS, pois possibilita aos disseminadores a utilização de metodologia de ensino compatíveis com a forma de aprender dos operadores. Os resultados desta pesquisa são semelhantes aos apresentados por Cerqueira (2000), Loo (2004), Kolb e Kolb (2005), Hamann (2011), para profissionais e estudantes das áreas de negócios, contabilidade e administração.

\section{CONSIDERAÇÕES FINAIS}

Entidades governamentais poderiam usar valores culturais e estilos de aprendizagem para planejarem as melhores estratégias de formatação dos treinamentos e disseminação voltados para a adoção das IPSAS. Os órgãos normatizadores e executores da contabilidade poderiam formatar suas políticas e estratégias de adoção das normas conforme os valores culturais e estilos de aprendizagem predominantes dos 'operadores da contabilidade'.

A comunidade epistêmica envolvida no desenho ou ensino das normas (normatizadores) e na operação e adoção (executores federal, estadual e municipal) apresentam os seguintes comportamentos de valores culturais predominantes que podem impactar o processo de adoção das IPSAS: (a) distância hierárquica equilibrada; (b) coletivismo; (c) feminilidade; (d) baixa aversão à incerteza; e (e) alta orientação de longo prazo. São características de pessoas que preferem ambiente de trabalho coletivista; chefes menos autoritários e que dialogam com seus subordinados; priorizam oportunidades de treinamentos para melhorar as habilidades; acentua-se a igualdade, a solidariedade e a qualidade de vida no trabalho; entendem que os conflitos devem ser resolvidos por meio da negociação e do compromisso.

Quanto a aprendizagem, observamos diferenças estatísticas significativas. O estilo de aprendizagem 'assimilador', baseado em raciocínio indutivo e modelos abstratos e teóricos, é predominante entre os normatizadores e executores federal e estadual. Contudo, operadores municipais tem aprendizado baseado em experiência concreta com uso de casos práticos. Isso não significa que um estilo é melhor ou pior que outro. Conhecer o estilo predominante possibilita aos professores e as entidades desenvolverem a didática de ensino mais adequada para cada especificidade da aprendizagem.

Caso não seja levado em consideração essas características predominantes dos aspectos estruturais do ciclo de aprendizagem, a disseminação (treinamentos, cursos e debates) das normas pode encontrar dificuldades de aprendizagem por parte da maioria dos operadores, pois a utilização da metodologia de ensino que não leve em consideração a forma como os aprendizes aprendem atrasará o processo da reforma.

Pesquisas futuras poderão analisar se as entidades consideram o comportamento dos 'operadores da contabilidade' do setor público no processo de aprendizagem organizacional, para incrementar as práticas dos indivíduos nas organizações. Há, ainda, a possibilidade de pesquisa que verifique qual o grau de enforcement e nível de incentivos coercitivos para que os gestores priorizem a adoção das IPSAS.

\section{REFERÊNCIAS}

Antipova, T., \& Bourmistrov, A. (2013). Is Russian public sector accounting in the process of modernization? An analysis of accounting reforms in Russia. Financial Accountability \& Management, 29(4), 442-478. DOI: https://doi.org/10.1111/faam.12021

Antonello, C. S., \& Schmidt Godoy, A. (2010). A encruzilhada da aprendizagem organizacional: uma visão multiparadigmática. RAC-Revista de Administração Contemporânea, 14(2). DOI: http://dx.doi.org/10.1590/ S1415-65552010000200008

Argyris, C., \& Schön, D. (1978). Organizational learning: a theory of action perspective. Reading, Massachusetts: Addison-Wesley.

Brasil. (2016). Ministério da Fazenda. Secretaria do Tesouro Nacional. Avanços Recentes e Perspectivas da Convergência aos Padrões Internacionais de Contabilidade do Setor Público. Brasília: MF/STN.

Benito, B., Brusca, I., \& Montesinos, V. (2007). The harmonization of government financial information systems: the role of the IPSASs. International Review of Administrative Sciences, v. 73, n. 2, p. 293-317. DOI: https:// doi.org/10.1177/0020852307078424 
Brusca, I., \& Condor, V. (2002). Towards the harmonisation of local accounting systems in the international context. Financial Accountability \& Management, v. 18, n. 2, p. 129-162. DOI: https://doi.org/10.1111/14680408.00148

Cerqueira, T. C. S. (2000). Estilos de aprendizagem em universitários. Belo Horizonte: Cuatiara, v. 34.

Christiaens, J., Vanhee, C., Manes-Rossi, F., Aversano, N., \& Van Cauwenberge, P. (2015). The effect of IPSAS on reforming governmental financial reporting: An international comparison. International Review of Administrative Sciences, v. 81, n. 1, p. 158-177. DOI: https://doi.org/10.1177/0020852314546580

Diniz, J. A., Silva, S. F. S., Costa Santos, L., \& Martins, V. G. (2015). Vantagens da Implantação das IPSAS na Contabilidade pública brasileira: análise da percepção dos membros do GTCON. Revista de Educação e Pesquisa em Contabilidade (REPeC), v. 9, n. 3. DOI: https://doi.org/10.17524/repec.v9i3.1226

Gray, S. J. (1988). Towards a theory of cultural influence on the development of accounting systems internationally. Abacus, v. 24, n. 1, p. 1-15.

Hamann, E. V. (2011). Influência cultural sobre os estilos de aprendizagem dos estudantes de Ciências Contábeis do Distrito Federal: um estudo empírico sobre as abordagens de Hofstede e Kolb. 123 f. Dissertação, Programa Multi-institucional e Inter-regional de Pós-graduação em Ciências Contábeis, UnB/UFPB/UFRN, Brasília.

Hofstede, G. (1980/1986). Culture's consequences: international differences in work-related values. London: Sage Publications.

(2001). Culture's consequences: comparing values, behaviors, institutions, and organizations across nations. 2. ed. London: Sage Publications.

International Federation of Accountants. (1996). Responding to an increasing demand for accountability in the public sector. New York: IFAC Quarterly.

Jorge, S. M. F. (2003). Local government accounting in Portugal in comparative-international perspective. $\mathrm{Ph}$. D Thesis, Department of Accounting and Finance, Birmingham Business School, The University of Birmingham, Birmingham.

Kolb, D. A. (1971). Individual learning styles and the learning process. Massachusetts: Sloan School of Management.

. (1984). Experimental learning: experience as the source of learning and development. New Jersey: Prentice-Hall, Englewood Cliffs.

(1999). Learning style inventory. Version 3. Boston: TRG Hay/McBer.

Kolb, A. Y., \& Kolb, D. A. (2005). Learning styles and learning spaces: enhancing experiential learning in higher education. Academy of Management Learning \& Education, v. 4, n. 2, p. 193-212. DOI: http://dx.doi. org/10.5465/AMLE.2005.17268566

Loo, R. (2004). Kolb's learning styles and learning preferences: is there a linkage? Educational Psychology, v. 24 , n. 1, p. 99-108. DOI: https://doi.org/10.1080/0144341032000146476

Pina, V., \& Torres, L. (2003). Reshaping public sector accounting: an international comparative view. Canadian Journal of Administrative Sciences/Revue Canadienne des Sciences de l'Administration, v. 20, n. 4, p. 334350. DOI: https://doi.org/10.1111/j.1936-4490.2003.tb00709.x

Pina, V., Torres, L., \& Yetano,A.(2009). Accrual accounting in EUlocal governments: one method, several approaches. European Accounting Review, v. 18, n. 4, p. 765-807. DOI: https://doi.org/10.1080/09638180903118694

Radebaugh, L. H., \& Gray, S. J. (1997/2002). International Accounting and Multinational Enterprises. 4. ed. New York: John Wiley \& Sons.

Rodrigues, I. (2010). Cultura e desempenho de equipes de projetos globais: um estudo em empresas multinacionais brasileiras. Tese (Doutorado em Contabilidade) (Doutorado em Ciências Contábeis) - Faculdade de Economia, Administração e Contabilidade da Universidade de São Paulo, São Paulo.

Tung, R. (2008). The cross-cultural research imperative: the need to balance cross-national and intra-national diversity. Journal of International Business Studies, v. 39, p. 41-46. DOI: https://doi.org/10.1057/palgrave. jibs. 8400331 
Weffort, E. F. J. (2005). O Brasil e a harmonização contábil internacional: influências dos sistemas jurídico e educacional, da cultura e do mercado. São Paulo: Atlas, 231 p. Tese (Doutorado em Controladoria e Contabilidade) - Departamento de Contabilidade e Atuária, FEA-USP

\section{Como citar este artigo}

Silva Neto, A. F. da; \& Silva, J. D. G. da. (2019). Valores culturais e estilos de aprendizagem dos operadores da contabilidade do setor público brasileiro frente ao processo de adoção das normas internacionais. Revista de Contabilidade e Organizações, 13:e144322. DOI: http://dx.doi.org/10.11606/issn.1982-6486. rco.2019.144322

\section{APÊNDICE A - Questionário}

Pesquisa acadêmica sobre "Valores culturais e estilos aprendizagem dos operadores da contabilidade do setor público brasileiro frente ao processo de adoção das normas internacionais"

\section{Prezado(a)}

O objetivo desta carta é convidá-lo(a) a participar de uma pesquisa para investigar os valores culturais e os estilos de aprendizagem dos operadores da contabilidade do setor público brasileiro frente ao processo de adoção das Normas Internacionais de Contabilidade, mais especificamente as International Public Sector Accounting Standards (IPSAS, sigla em inglês).

O público-alvo é composto pelos operadores da contabilidade do setor público (contabilista, auditor, auditor fiscal, assessor e analista). O questionário é composto por duas seções: (1) dados gerais dos respondentes e dimensões culturais; (2) estilos de aprendizagem.

O tempo estimado para se concluir o preenchimento do questionário é de 10 a 15 minutos.

Suas respostas serão utilizadas apenas para fins acadêmicos. Os respondentes não serão identificados por nome. O seu feedback é valioso e o apoio é muito apreciado. Entre em contato se precisar de mais informações sobre o estudo. Contato: antonio.firminoneto@gmail.com.

Com os melhores cumprimentos.

\section{Termo de consentimento - Marque com um "X"}

\begin{tabular}{|l|l|}
\hline & $\begin{array}{l}\text { Confirmo que li e compreendi o objetivo da pesquisa e que me foi dada a oportunidade, por e-mail ou presencialmente, } \\
\text { de fazer perguntas. }\end{array}$ \\
\hline & $\begin{array}{l}\text { Entendo que a minha participação é voluntária e que eu sou livre para retirar o meu consentimento e descontinuar a } \\
\text { minha participação nesta pesquisa a qualquer momento. }\end{array}$ \\
\hline & Concordo em participar da pesquisa. \\
\hline
\end{tabular}


Valores culturais e estilos aprendizagem dos operadores da contabilidade do setor público brasileiro frente ao processo de adoção das normas internacionais

\section{SEÇÃO 1 - DADOS GERAIS DO RESPONDENTE E DIMENSÕES CULTURAIS}

\begin{tabular}{|c|c|}
\hline Nome & \\
\hline \multicolumn{2}{|l|}{ E-mail } \\
\hline Sexo & ( ) Masculino ( ) Feminino \\
\hline Faixa etária & ( ) 18 a 25 ( ) 26 a 35 ( ) 36 a 45 ( ) 46 a 55 ( ) mais de 56 \\
\hline Tipo de entidade pública em que atua & $\begin{array}{l}\text { ( ) Federal } \\
\text { ( ) Estadual e DF } \\
\text { ( ) Municipal } \\
\end{array}$ \\
\hline \multicolumn{2}{|l|}{ Em qual entidade atua } \\
\hline $\begin{array}{l}\text { Em qual cidade e estado está localizada a entidade } \\
\text { na qual atua }\end{array}$ & $\begin{array}{l}\text { Cidade: } \\
\text { UF: }\end{array}$ \\
\hline Formação Acadêmica & $\begin{array}{l}\text { ( ) Médio-Técnico em contabilidade } \\
\text { ( ) Graduação - Qual? } \\
\text { ( ) Especialização } \\
\text { ( ) Mestrado } \\
\text { ( ) Doutorado }\end{array}$ \\
\hline $\begin{array}{l}\text { Experiência com contabilidade do setor público } \\
\text { (anos). }\end{array}$ & $\begin{array}{l}\text { ( ) até } 2 \\
\text { ( ) } 3-5 \\
\text { ( ) } 6-10 \\
\text { ( ) } 11-15 \\
\text { ( ) } 15 \text { ou mais }\end{array}$ \\
\hline Participa/participou de algum destes grupos & $\begin{array}{l}\text { ( ) GTCON } \\
\text { ( ) Gefin } \\
\text { ( ) Gestores Financeiros das Capitais }\end{array}$ \\
\hline Considera ser um profissional do ciclo & $\begin{array}{l}\text { ( ) Gestão } \\
\text { ( ) Operacional } \\
\text { ( ) Outros }\end{array}$ \\
\hline
\end{tabular}

Assinale a resposta que considerar mais indicada para cada item, conforme o grau de importância abaixo:

\begin{tabular}{|c|c|c|c|c|}
\hline $\begin{array}{c}1-\text { Mínima } \\
\text { importância }\end{array}$ & $\begin{array}{c}2 \text { - Pouco } \\
\text { importante }\end{array}$ & $\begin{array}{c}3 \text { - Importância } \\
\text { moderada }\end{array}$ & 4 - Muito importante & $\begin{array}{c}5-\text { Máxima } \\
\text { importância }\end{array}$ \\
\hline
\end{tabular}

Você desenvolve suas atividades profissionais de contabilidade para uma (ou em uma) entidade do setor público. No desenvolvimento de suas atividades profissional, pessoal e familiar, qual importância você atribui a cada uma das seguintes características?

\begin{tabular}{|c|c|c|c|c|c|c|}
\hline 1 & Tempo suficiente para a vida pessoal e familiar. & 1 & 2 & 3 & 4 & 5 \\
\hline 2 & $\begin{array}{l}\text { Ter boas condições físicas do ambiente de trabalho (boa ventilação e } \\
\text { iluminação, espaço de estudo etc.) }\end{array}$ & 1 & 2 & 3 & 4 & 5 \\
\hline 3 & Ter boa relação com seu chefe. & 1 & 2 & 3 & 4 & 5 \\
\hline 4 & Conseguir apenas a progressão na carreira. & 1 & 2 & 3 & 4 & 5 \\
\hline 5 & Trabalhar com pessoas que saibam colaborar umas com as outras. & 1 & 2 & 3 & 4 & 5 \\
\hline 6 & Ser consultado pelo chefe sobre as decisões que ele deva tomar. & 1 & 2 & 3 & 4 & 5 \\
\hline 7 & Ter oportunidade de progredir na carreira profissional. & 1 & 2 & 3 & 4 & 5 \\
\hline 8 & $\begin{array}{l}\text { Ter um trabalho que inclua experiências variadas e que tenha um } \\
\text { elemento de aventura. }\end{array}$ & 1 & 2 & 3 & 4 & 5 \\
\hline
\end{tabular}


Na sua vida privada, qual a importância de cada uma das seguintes características?

\begin{tabular}{|c|l|l|l|l|l|l|}
\hline 9 & Estabilidade e tranquilidade pessoal. & 1 & 2 & 3 & 4 & 5 \\
\hline 10 & Ponderação no gasto com dinheiro. & 1 & 2 & 3 & 4 & 5 \\
\hline 11 & Persistência (perseverança). & 1 & 2 & 3 & 4 & 5 \\
\hline 12 & Respeito pela tradição e valores. & 1 & 2 & 3 & 4 & 5 \\
\hline
\end{tabular}

\begin{tabular}{|c|c|c|c|c|}
\hline \multicolumn{5}{|c|}{13 - Com que frequência se sente nervoso ou tenso com seu trabalho? } \\
\hline 1 & 2 & 3 & 4 & 5 \\
\hline Nunca & Raramente & Algumas vezes & Frequentemente & Sempre \\
\hline \multicolumn{5}{|c|}{} \\
\hline \multicolumn{5}{|c|}{ relação aos seus chefes? } \\
\hline 14 - Pela sua experiência, com que frequência seus colegas de trabalho sentem receio de exprimir o seu desacordo em \\
\hline \multicolumn{5}{|c|}{} \\
\hline Nunca & Raramente & Algumas vezes & Frequentemente & Sempre \\
\hline
\end{tabular}

Qual o seu grau de concordância em relação a estrutura organizacional, ao seu chefe e aos colegas de trabalho? (Por favor, utilize a escala do item 14 para os itens de 15 a 20).

\begin{tabular}{|c|c|c|c|c|c|c|}
\hline 15 & A maioria dos colegas de trabalho é confiável. & 1 & 2 & 3 & 4 & 5 \\
\hline 16 & $\begin{array}{l}\text { Uma pessoa pode ser uma gestora sem ter uma resposta precisa } \\
\text { para toda pergunta que um subordinado pode fazer a respeito de seu } \\
\text { trabalho. }\end{array}$ & 1 & 2 & 3 & 4 & 5 \\
\hline 17 & $\begin{array}{l}\text { Uma estrutura organizacional em que os subordinados têm dois chefes } \\
\text { deve ser evitada a qualquer custo. }\end{array}$ & 1 & 2 & 3 & 4 & 5 \\
\hline 18 & $\begin{array}{l}\text { A competição entre os colegas gera, frequentemente, mais } \\
\text { inconvenientes que benefícios. }\end{array}$ & 1 & 2 & 3 & 4 & 5 \\
\hline 19 & $\begin{array}{l}\text { As regras e normas do órgão não devem ser quebradas, nem mesmo } \\
\text { quando você julgue que é do interesse do órgão. }\end{array}$ & 1 & 2 & 3 & 4 & 5 \\
\hline 20 & Quando as pessoas falham é, frequentemente, por culpa própria. & 1 & 2 & 3 & 4 & 5 \\
\hline
\end{tabular}

\section{SEÇÃO 2 - INVENTÁRIO ESTILOS DE APRENDIZAGEM DE DAVID KOLB}

(Versão traduzida por Cerqueira, 2000)

O questionário de estilo de aprendizagem descreve a maneira como você aprende e como você lida com ideias e as situações do dia a dia em sua vida. Abaixo, você encontrará 12 sentenças. Cada sentença tem quatro terminações (A, B, C, D). Classifique as terminações de cada sentença de forma a retratar a maneira como você atua ao ter que aprender algo.

Antes de começar a responder, imagine que você desenvolve suas atividades profissionais de contabilidade para uma (ou em uma) entidade do setor público. A contabilidade do setor público está passando por mudanças de normatização. Será necessária a adoção de normas internacionais (IPSAS). Portanto, será necessário "aprender".

Então, fazendo uso do espaço disponível, classifique com "4" a terminação da sentença que descreve a sentença como você aprende melhor, descendo até chegar a "1" para a terminação da sentença que você considera que é a maneira menos provável como você aprenderia algo. Dê uma resposta para cada uma das quatro terminações. Não repita valores na mesma sentença. 
Exemplo de uma sentença completa:

\begin{tabular}{|l|l|l|l|l|l|l|l|l|l|}
\hline I & & A & & B & & C & & D & \\
\cline { 2 - 9 } & $\begin{array}{c}\text { Quando eu } \\
\text { aprendo: }\end{array}$ & $\mathbf{2}$ & $\begin{array}{c}\text { Gosto de lidar } \\
\text { com meus } \\
\text { sentimentos }\end{array}$ & 1 & $\begin{array}{c}\text { Gosto de } \\
\text { pensar sobre } \\
\text { ideias }\end{array}$ & 3 & $\begin{array}{c}\text { Gosto de fazer } \\
\text { coisas }\end{array}$ & 4 & $\begin{array}{c}\text { Gosto de ver } \\
\text { e escutar }\end{array}$ \\
\hline
\end{tabular}

\section{Lembre-se:}

4 = a maneira como você aprende melhor;

3 = segunda melhor maneira como você aprende;

2 = terceira melhor maneira como você aprende;

1 = maneira menos provável como você aprende.

\begin{tabular}{|c|c|c|c|c|c|c|c|c|c|}
\hline & & A & & B & & $\mathrm{C}$ & & D & \\
\hline 1 & $\begin{array}{l}\text { Quando eu } \\
\text { aprendo: }\end{array}$ & & $\begin{array}{c}\text { Gosto de lidar } \\
\text { com meus } \\
\text { sentimentos }\end{array}$ & & $\begin{array}{c}\text { Gosto de } \\
\text { pensar sobre } \\
\text { ideias }\end{array}$ & & $\begin{array}{l}\text { Gosto de fazer } \\
\text { coisas }\end{array}$ & & $\begin{array}{l}\text { Gosto de ver } \\
\text { e escutar }\end{array}$ \\
\hline 2 & $\begin{array}{c}\text { Eu aprendo } \\
\text { melhor } \\
\text { quando: }\end{array}$ & & $\begin{array}{c}\text { Escuto e } \\
\text { observo } \\
\text { atentamente }\end{array}$ & & $\begin{array}{l}\text { Utilizo o } \\
\text { raciocínio } \\
\text { lógico }\end{array}$ & & $\begin{array}{c}\text { Confio nos } \\
\text { meus palpites e } \\
\text { sentimentos }\end{array}$ & & $\begin{array}{l}\text { Trabalho } \\
\text { muito para } \\
\text { fazer as } \\
\text { coisas. }\end{array}$ \\
\hline 3 & $\begin{array}{c}\text { Quando } \\
\text { estou } \\
\text { aprendendo: }\end{array}$ & & $\begin{array}{l}\text { Tendo a dar } \\
\text { razão para as } \\
\text { coisas }\end{array}$ & & $\begin{array}{c}\text { Sou } \\
\text { responsável } \\
\text { com as coisas }\end{array}$ & & $\begin{array}{l}\text { Fico quieto e } \\
\text { reservado }\end{array}$ & & $\begin{array}{l}\text { Tenho fortes } \\
\text { sentimentos e } \\
\text { reações }\end{array}$ \\
\hline 4 & $\begin{array}{c}\text { Eu aprendo } \\
\text { por: }\end{array}$ & & Sentindo & & Fazendo & & Assistindo & & Pensando \\
\hline 5 & $\begin{array}{c}\text { Quando } \\
\text { estou } \\
\text { aprendendo: }\end{array}$ & & $\begin{array}{c}\text { Estou aberto } \\
\text { para novas } \\
\text { experiências }\end{array}$ & & $\begin{array}{c}\text { Observo todos } \\
\text { os lados dos } \\
\text { problemas }\end{array}$ & & $\begin{array}{c}\text { Analiso as } \\
\text { coisas por partes } \\
\text { minuciosas }\end{array}$ & & $\begin{array}{l}\text { Gosto de } \\
\text { testar }\end{array}$ \\
\hline 6 & $\begin{array}{c}\text { Quando } \\
\text { estou } \\
\text { aprendendo: }\end{array}$ & & $\begin{array}{c}\text { Sou uma } \\
\text { pessoa } \\
\text { observadora }\end{array}$ & & $\begin{array}{l}\text { Sou uma } \\
\text { pessoa ativa }\end{array}$ & & $\begin{array}{l}\text { Sou uma pessoa } \\
\text { intuitiva }\end{array}$ & & $\begin{array}{c}\text { Sou uma } \\
\text { pessoa lógica }\end{array}$ \\
\hline 7 & $\begin{array}{l}\text { Aprendo } \\
\text { melhor } \\
\text { quando: }\end{array}$ & & Observo & & $\begin{array}{c}\text { Relaciono } \\
\text { com outras } \\
\text { pessoas } \\
\end{array}$ & & $\begin{array}{l}\text { Utilizo teorias } \\
\text { racionais }\end{array}$ & & $\begin{array}{l}\text { Tento e } \\
\text { pratico }\end{array}$ \\
\hline 8 & $\begin{array}{l}\text { Quando eu } \\
\text { aprendo: }\end{array}$ & & $\begin{array}{l}\text { Gosto de ver } \\
\text { os resultados } \\
\text { do meu } \\
\text { trabalho }\end{array}$ & & $\begin{array}{l}\text { Gosto de } \\
\text { ideias e } \\
\text { teorias }\end{array}$ & & $\begin{array}{c}\text { Utilizo meu } \\
\text { tempo antes de } \\
\text { agir }\end{array}$ & & $\begin{array}{c}\text { Sinto-me } \\
\text { envolvido } \\
\text { com as coisas }\end{array}$ \\
\hline 9 & $\begin{array}{c}\text { Eu aprendo } \\
\text { melhor } \\
\text { quando: }\end{array}$ & & $\begin{array}{c}\text { Confio nas } \\
\text { minhas } \\
\text { observações }\end{array}$ & & $\begin{array}{c}\text { Confio } \\
\text { nos meus } \\
\text { sentimentos } \\
\end{array}$ & & $\begin{array}{l}\text { Tento por conta } \\
\text { própria }\end{array}$ & & $\begin{array}{l}\text { Confio nas } \\
\text { minhas ideias }\end{array}$ \\
\hline 10 & $\begin{array}{c}\text { Quando } \\
\text { estou } \\
\text { aprendendo: }\end{array}$ & & $\begin{array}{l}\text { Eu sou } \\
\text { uma pessoa } \\
\text { reservada }\end{array}$ & & $\begin{array}{l}\text { Eu sou uma } \\
\text { pessoa aberta }\end{array}$ & & $\begin{array}{c}\text { Eu sou } \\
\text { uma pessoa } \\
\text { responsável }\end{array}$ & & $\begin{array}{c}\text { Eu sou } \\
\text { uma pessoa } \\
\text { racional }\end{array}$ \\
\hline 11 & $\begin{array}{c}\text { Quando } \\
\text { estou } \\
\text { aprendendo: }\end{array}$ & & $\begin{array}{l}\text { Eu fico } \\
\text { envolvido }\end{array}$ & & $\begin{array}{l}\text { Eu gosto de } \\
\text { observar }\end{array}$ & & $\begin{array}{c}\text { Eu gosto de } \\
\text { avaliar as coisas }\end{array}$ & & $\begin{array}{l}\text { Eu gosto de } \\
\text { ser ativo }\end{array}$ \\
\hline 12 & $\begin{array}{c}\text { Eu aprendo } \\
\text { melhor } \\
\text { quando: }\end{array}$ & & $\begin{array}{l}\text { Analiso as } \\
\text { ideias }\end{array}$ & & $\begin{array}{l}\text { Sou receptivo } \\
\text { e aberto }\end{array}$ & & Fico cuidadoso & & Sou prático \\
\hline
\end{tabular}

Fonte: Copyright 1985 David Kolb revised 1999. Versão adaptada da tradução de Cerqueira (2000).

Cerqueira, T. C. S. (2000). Estilos de aprendizagem em universitários. Belo Horizonte: Cuatiara, v. 34. 
APÊNDICE B - Descrição da Amostra

A amostra desta pesquisa é composta por 426 'operadores da contabilidade' do setor público brasileiro que identificamos serem envolvidos no desenho ou ensino das normas' (normatizadores) e aqueles 'envolvidos na operação e adoção' (executores) das IPSAS no Brasil. A escolha desses profissionais se deu por se entender que eles podem demonstrar os estilos de aprendizagem e dimensões culturais predominantes que podem impactar no processo de adoção das IPSAS. As Tabelas 1 a 6 descrevem a amostra.

Tabela 1. Perfil do sexo dos operadores da contabilidade

\begin{tabular}{ccc}
\hline Sexo & Quantidade & \% \\
\hline Masculino & 247 & 57,98 \\
Feminino & 179 & 42,02 \\
\hline Total & 426 & 100 \\
\hline
\end{tabular}

Fonte: Dados da pesquisa.

Tabela 2. Faixa etária e anos de experiência dos operadores da contabilidade

\begin{tabular}{|c|c|c|c|c|}
\hline Variáveis & Categorias & Quantidade & $\%$ & $\%$ acumulado \\
\hline \multirow{5}{*}{ Faixa etária (anos) } & 18 a 25 & 17 & 3,99 & 3,99 \\
\hline & 26 a 35 & 129 & 30,28 & 34,27 \\
\hline & 36 a 45 & 161 & 37,79 & 72,06 \\
\hline & 46 a 55 & 100 & 23,47 & 95,53 \\
\hline & 56 ou mais & 19 & 4,47 & 100,00 \\
\hline \multirow{5}{*}{ Experiência (anos) } & Até 2 & 62 & 14,55 & 14,55 \\
\hline & 3 a 5 & 70 & 16,43 & 30,98 \\
\hline & 6 a 10 & 117 & 27,47 & 58,45 \\
\hline & 11 a 15 & 78 & 18,31 & 76,76 \\
\hline & Mais de 15 & 99 & 23,24 & 100 \\
\hline
\end{tabular}

Fonte: Dados da pesquisa.

Tabela 3. Tipo de entidade pública e órgão onde os operadores da contabilidade atuam

\begin{tabular}{clcc}
\hline \multicolumn{1}{c}{ Variáveis } & \multicolumn{1}{c}{ Categorias } & Quantidade & \% \\
\hline \multirow{2}{*}{ Tipo de ente federativo } & Federal & 176 & 41,31 \\
& Estadual & 107 & 25,12 \\
& Municipal & 143 & 33,57 \\
\hline \multirow{2}{*}{ Órgão } & Secretaria do Tesouro Nacional & 22 & 5,17 \\
& Tribunais de Contas & 34 & 7,98 \\
& Universidades & 32 & 7,51 \\
& Institutos Federais & 28 & 6,57 \\
& Agências Reguladoras & 24 & 5,63 \\
& Ministérios & 23 & 5,40 \\
& Secretárias de Fazenda & 20 & 4,70 \\
& Outros & 243 & 57,04 \\
\hline
\end{tabular}

Fonte: Dados da pesquisa.

Nota: A maioria (outros $=57,04 \%$ ) atua em órgãos estaduais e municipais da Administração direta e indireta, tais como: secretarias, fundos, fundações e autarquias. 
Tabela 4. Grupo ao qual pertence os operadores da contabilidade

\begin{tabular}{clccc}
\hline Variável & \multicolumn{1}{c}{ Categorias } & Quantidade & \% & \% acumulado \\
\hline \multirow{4}{*}{ Grupo } & Normatizador & 137 & 32,16 & 32,16 \\
& Executor contabilidade federal & 140 & 32,86 & 65,02 \\
& Executor contabilidade estadual & 33 & 7,75 & 72,77 \\
& Executor contabilidade municipal & 116 & 27,23 & 100 \\
\hline
\end{tabular}

Fonte: Dados da pesquisa.

Tabela 5. Região onde os operadores da contabilidade atuam

\begin{tabular}{clccc}
\hline Variável & \multicolumn{1}{c}{ Categorias } & Quantidade & $\mathbf{\%}$ & \% acumulado \\
\hline \multirow{6}{*}{ Região } & Norte & 30 & 7,05 & 7,05 \\
& Nordeste & 70 & 16,43 & 23,48 \\
& Sudeste & 51 & 11,97 & 35,45 \\
& Sul & 150 & 35,21 & 70,66 \\
& Centro-Oeste & 125 & 29,34 & 100 \\
\hline
\end{tabular}

Fonte: Dados da pesquisa.

Tabela 6. Grau de formação e especificação do curso superior e médio/técnico

\begin{tabular}{clccc}
\hline \multicolumn{1}{c}{ Variáveis } & \multicolumn{1}{c}{ Categorias } & Quantidade & \% & \% acumulado \\
\hline \multirow{4}{*}{ Grau de formação } & Médio/Técnico em Contabilidade & 8 & 1,88 & 1,88 \\
& Graduação & 105 & 24,65 & 26,53 \\
& Especialização & 249 & 58,45 & 84,98 \\
& Mestrado & 60 & 14,08 & 99,06 \\
& Doutorado & 4 & 0,94 & 100,00 \\
\hline & Ciências Contábeis (somente) & 360 & 84,51 & 84,51 \\
& Ciências Contábeis e outra formação & 10 & 2,35 & 86,86 \\
Curso superior ou & Administração e Economia & 15 & 3,52 & 90,38 \\
& Direito & 6 & 1,41 & 91,79 \\
& Engenharia, Computação e Matemática & 10 & 2,35 & 94,14 \\
& Gestão Pública & 10 & 2,35 & 96,49 \\
& Ciências Humanas & 7 & 1,63 & 98,12 \\
& Médio/Técnico & 8 & 1,88 & 100 \\
\hline
\end{tabular}

Fonte: Dados da pesquisa. 